\title{
Neuropsychological Evaluation and Cerebral Blood Flow Effects of Apolipoprotein E4 in Alzheimer's Disease Patients after One Year of Treatment: An Exploratory Study
}

\author{
Azusa Suwa $^{a}$ Keiichiro Nishida ${ }^{a}$ Keita Utsunomiyab Shinpei Nonen ${ }^{\mathrm{c}}$ \\ Masafumi Yoshimura ${ }^{a}$ Yoshiteru Takekita ${ }^{a} d \quad$ Masataka Wakeno $^{a}$ \\ Aran Tajika $^{a}$ Maki Yoshino $^{a}$ Yosuke Koshikawa $^{a}$ Masaki Kato ${ }^{a}$ \\ Toshihiko Kinoshita ${ }^{a}$

\begin{abstract}
Departments of a Neuropsychiatry and ${ }^{\mathrm{b}}$ Radiology, Kansai Medical University, Osaka, and 'Department of Pharmacy, School of Pharmacy, Hyogo University of Health Sciences, Hyogo, Japan; d Department of Biomedical and NeuroMotor Science, University of Bologna,
\end{abstract} \\ Bologna, Italy
}

\section{Key Words}

Alzheimer's disease - Single-photon emission computed tomography - Apolipoprotein E ·

Alzheimer's Disease Assessment Scale · Cognitive function · Donepezil

\begin{abstract}
Background: Alzheimer's disease (AD) is affected by apolipoprotein E (ApoE); however, its effects assessed by means of cognitive tests and by neuroimaging have not been sufficiently studied. Methods: We administered the Alzheimer's Disease Assessment Scale (ADAS) and single-photon emission computed tomography imaging in patients with AD medicated with donepezil at baseline and after 1 year. Patients were classified as with or without ApoE4 and we evaluated the progress of AD. Results: Analysis of covariance showed that cerebral blood flow after 1 year in subjects with ApoE4 is significantly reduced in some areas including the left lenticular nucleus, left thalamus, and right hippocampus compared with subjects without ApoE4. Paired t tests showed significantly reduced blood flow in several regions including the right hippocampus in subjects with ApoE4 and significant deterioration of ideational praxis in subjects without ApoE4. Conclusion: This study provides evidence that supports the notion of ApoE4 playing an important role in the progress of AD.

(C) 2015 S. Karger AG, Basel
\end{abstract}




\section{Introduction}

Alzheimer's disease (AD) is a degenerative disease that gradually reduces cognitive function, impairing the patient's social life. The clinical presentation of typical AD centers on memory impairment. Over the course of the disease, other cognitive functions, e.g., language, behavior, space recognition, and executive function, become impaired, resulting in a state of overall cognitive impairment [1]. Cholinesterase inhibitors including donepezil (DNP) are widely used, and $5 \mathrm{mg}$ is one of the most common dosages for delaying the progress of $\mathrm{AD}[2]$.

Representative memory tests for AD include the Mini-Mental State Examination (MMSE) [3] and Alzheimer's Disease Assessment Scale (ADAS) [4]. The MMSE is simple and most frequently used for screening. The ADAS is used for the follow-up of long-term symptoms, with the ADAS subscale for orientation impairment being most sensitive for assessing the progression of AD [5], and the ADAS subscale for ideational praxis and orientation being clinically associated with executive function impairment in AD [6].

With respect to imaging tools, single-photon emission computed tomography (SPECT) for cerebral blood flow measurement is one of the most representative neuroimaging tools for the diagnosis and progress of dementia. In the early stage of $\mathrm{AD}$, reduced blood flow is observed in the posterior cingulate gyrus and the precuneus. As the pathology progresses, reduced blood flow is observed in the vertex and the temporal association cortex $[7,8]$.

Both of these examinations, namely cognitive tests and neuroimaging tools, are quite reliable and useful from the clinical viewpoint, although neurocognitive evaluation and brain imaging often show different results, especially in the assessment of the progress of dementia. For example, cerebral blood flow in patients with AD sometimes shows an apparent decline during only few months, whereas ADAS score had been changing marginally in the same period. Opposite results are also common. These contradictory indicators contribute to confusion when deciding on the course of treatment.

On the other hand, from the view of gene polymorphism, apolipoprotein E (ApoE) $\varepsilon 4$ represents a major risk factor for $\mathrm{AD}$ [9]. There are three types of ApoE: ApoE2, ApoE3, and ApoE4, and each has corresponding alleles of $\varepsilon 2, \varepsilon 3$, and $\varepsilon 4$, respectively, comprising 6 phenotypes. Among them, the presence or absence of ApoE4 is reported to be associated with age at onset $[10,11]$ and clinical symptoms in $\mathrm{AD}[12]$. In addition, ApoE4 is suggested to have effects on imaging examination findings such as SPECT and positron emission tomography [13]. Thus, we consider that the study of the relation between ApoE4 and the changes in cognitive tests and imaging evaluations over a certain time period is of great clinical importance. The aim of this study was to explore the difference between carriers and noncarriers of ApoE4, in terms of changes in ADAS scores and SPECT images in AD patients. For this purpose, we examined the effects of ApoE4 on changes in cognitive function and cerebral blood flow in 1 year.

\section{Methods}

The study was reviewed and approved by the Ethics Committee of Kansai Medical University (Hi0806).

\section{Subjects}

The subjects enrolled in the study were 28 patients who had visited the Department of Neuropsychiatry, Kansai Medical University Takii Hospital and had been given a diagnosis of $\mathrm{AD}$ according to the diagnostic criteria of the National Institute of Neurological and Commu- 
Suwa et al.: Neuropsychological Evaluation and Cerebral Blood Flow Effects of ApoE4 in AD Patients after One Year of Treatment

nicative Diseases and Stroke/Alzheimer's Disease and Related Disorders Association (NINCDS-ADRDA) [14], with the exclusion of neuropathological diagnosis, mood disorder, schizophrenia, and anxiety disorder. All subjects provided written informed consent to the purpose of the study, with 1 patient ( 4\%) not giving consent to ApoE4 measurement. 27 patients started with $3 \mathrm{mg}$ DNP, and dosing was flexible throughout the study period according to patient response and side effects. In addition, patients treated with $5 \mathrm{mg}$ DNP were recruited in order to obtain a similar pharmacological treatment. 13 patients $(\sim 29 \%)$ had to discontinue or dropped out within 12 months. As a result, data from a total of 14 subjects were analyzed. They were divided into two groups based on whether they carried or did not carry ApoE4 according to previous studies $[9,15,16]$.

Primary outcomes were the comparison of ADAS scores and blood flow by SPECT at the endpoint between subjects with and without ApoE4. Secondary outcomes were the mean changes of the ADAS and SPECT between baseline and endpoint in each subject with or without ApoE4.

\section{Measurements}

ADAS, MMSE, and SPECT were performed on all subjects at baseline, and their ApoE phenotype was determined from blood samples as described below. A follow-up of ADAS, MMSE, and SPECT was performed approximately 12 months later (at endpoint), and changes were examined. For cognitive assessment, ADAS-Jcog, which is one of the standardized versions previously validated for Japanese, was used [17]. It includes 11 subscales: word recall, language, comprehension of spoken language, word finding difficulty, commands, object naming, constructional praxis, ideational praxis, orientation, word recognition, and remembering test instructions. For cerebral blood flow SPECT imaging, a ${ }^{99 \mathrm{~m}}$ Tc-ECD SPECT or ${ }^{123}$ I-IMP SPECT cerebral blood flow test was performed. A three-headed gamma camera (GCA-9300A; Toshiba, Tokyo, Japan) was used for data acquisition, and filtered back projection image reconstruction (System-5500, version 5.00; Toshiba, Tokyo, Japan) and Chang attenuation correction were performed using a ramp filter and Butterworth low-pass filter (order: 8; cutoff: ECD 0.16, IMP 0.14 cycle $/$ pixel, 1 pixel $=1.72 \mathrm{~mm}$ ). Software, a so-called three-dimensional stereotactic region of interest template (3DSRT), was used to analyze the region of interest of the cerebral blood flow date measured by SPECT $[18,19]$. 3DSRT can separate the cerebral hemispheres into 12 regions fully automatically: bilateral corpus callosum margin, precentral gyrus, center, vertex, angular gyrus, temporal lobe, posterior cerebrum, around the corpus callosum, lenticular nucleus, thalamus, hippocampus, and cerebellum. For SPECT images, the relative values of brain regions against the cerebellum were used for analysis.

\section{Genotyping and SNP Selection}

For ApoE genotyping, the fourth exon of ApoE gene including rs429358 (T/C, Cyc/Arg) and rs7412 (C/T, Arg/Cys) was amplified by PCR using primers reported by Singh et al. [20]. The amplified the product was analyzed by direct sequencing. We defined ApoE genotype of each subject according to the combination genotype of rs429358 and rs7412; $\mathrm{T}$ and $\mathrm{T}, \mathrm{T}$ and C, $C$ and $C$ were defined as $\varepsilon 2, \varepsilon 3, \varepsilon 4$, respectively.

\section{Data Analysis}

As a main outcome, analysis of covariance (ANCOVA) was performed to investigate the ADAS scores including subscale scores and the value of SPECT cerebral blood flow in a separated region of interest at endpoint. For removing the confounding variable, sex and evaluation values of ADAS and SPECT at baseline were set as dependent variables. Next, we compared the rate of SPECT cerebral blood value and ADAS scores at baseline and endpoint using paired $t$ tests in each two groups: one with the ApoE4 carriers and the other one with 
Table 1. Clinical background of the study subjects \begin{tabular}{l|l}
\hline Dement Geriatr Cogn Disord Extra 2015;5:414-423 \\
\hline DOI: 10.1159/000440714 & $\begin{array}{l}\text { C } 2015 \text { S. Karger AG, Basel } \\
\text { www.karger.com/dee }\end{array}$ \\
\hline Suwa et al.: Neuropsychological Evaluation and Cerebral Blood Flow Effects of ApoE4
\end{tabular} Suwa et al.: Neuropsychological Evaluation
in AD Patients after One Year of Treatment

\begin{tabular}{|c|c|c|c|c|}
\hline & $\begin{array}{l}\text { ApoE4+ } \\
(\mathrm{n}=8)\end{array}$ & $\begin{array}{l}\text { ApoE4- } \\
(n=6)\end{array}$ & $\begin{array}{l}\mathrm{p} \\
\text { value }\end{array}$ & $\begin{array}{l}\text { All subjects } \\
(\mathrm{n}=14)\end{array}$ \\
\hline Females & $5(62.5)$ & $2(33)$ & $1^{\mathrm{a}}$ & $7(50)$ \\
\hline $\begin{array}{l}\text { Age at baseline, years } \\
\text { ADAS total score }\end{array}$ & $74.0 \pm 8.2$ & $73.5 \pm 6.2$ & $0.904^{\mathrm{b}}$ & $73.8 \pm 7.2$ \\
\hline $\begin{array}{c}\text { at baseline } \\
\text { ADAS total score }\end{array}$ & $18.4 \pm 5.3$ & $17.0 \pm 5.9$ & $0.653^{b}$ & $17.8 \pm 5.4$ \\
\hline at endpoint & $23.9 \pm 9.0$ & $22.6 \pm 11.4$ & $0.818^{\mathrm{b}}$ & $23.4 \pm 9.7$ \\
\hline MMSE at baseline & $18.0 \pm 3.7$ & $19.7 \pm 3.3$ & $0.399^{\mathrm{b}}$ & $18.7 \pm 3.5$ \\
\hline MMSE at endpoint & $16.4 \pm 4.0$ & $17.8 \pm 4.8$ & $0.544^{\mathrm{b}}$ & $17.0 \pm 4.2$ \\
\hline
\end{tabular}

Values are $n(\%)$ or mean \pm SD. ApoE4+ = Subjects with ApoE4; ApoE4- = subjects without ApoE4; $n=$ number of subjects with an assessment. ${ }^{\mathrm{a}} \chi^{2}$ test. ${ }^{\mathrm{b}}$ t test.

the noncarriers, respectively. $\chi^{2}$ tests were used to examine differences between categorical measures.

SPSS version 21.0J for Windows was used for the statistical analyses. The 5\% level of significance was used throughout all analyses.

\section{Results}

\section{Clinical Background}

The 14 subjects included 7 males and 7 females with no difference in gender ratio $(\mathrm{p}=$ 1 ). The mean age at baseline was $73.8 \pm 7.2$ years. The mean ADAS scores at baseline and at endpoint were $17.8 \pm 5.4$ and $23.4 \pm 9.7$ points. The mean MMSE scores at baseline and at endpoint were $18.7 \pm 3.5$ and $17.0 \pm 4.2$ points. The ApoE phenotypes were $\varepsilon 2 / \varepsilon 3$ in 1 patient (7\%), $\varepsilon 3 / \varepsilon 3$ in 5 (36\%), $\varepsilon 3 / \varepsilon 4$ in 8 (57\%), and $\varepsilon 2 / \varepsilon 2, \varepsilon 2 / \varepsilon 4$ and $\varepsilon 4 / \varepsilon 4$ in 0 , showing that 8 subjects carried ApoE4 and 6 did not carry ApoE4 (table 1).

Comparison of ADAS and SPECT between the Groups with and without ApoE4 at Endpoint ADAS

ADAS scores at endpoint showed no significant difference between the carriers and noncarriers of ApoE4.

\section{SPECT}

SPECT of subjects with ApoE4 at end point showed significantly reduced blood flow in the right corpus callosum margin $(p=0.022)$, left precentral gyrus $(p=0.041)$, left lenticular nucleus ( $\mathrm{p}=0.022)$, left thalamus $(\mathrm{p}=0.026)$, and right hippocampus $(\mathrm{p}=0.008)$ compared with subjects without ApoE4 (table 2).

Comparison of the ADAS and SPECT at Endpoint Compared to Baseline in the Groups with and without ApoE4

ADAS

The changes in ADAS scores at endpoint compared to baseline in all subjects showed significant deterioration in object naming ( $p=0.047)$, ideational praxis $(p=0.009)$, and orientation ( $p=0.043$; total score: $\mathrm{p}=0.021$ ). Of the subjects classified as with or without ApoE4, 
Table 2. Comparison of ADAS and SPECT at endpoint between subjects with and without ApoE4

\begin{tabular}{|c|c|c|c|c|}
\hline & \multirow{2}{*}{$\begin{array}{l}\text { ApoE4+ } \\
(n=8)\end{array}$} & \multirow{2}{*}{$\begin{array}{l}\text { ApoE4- } \\
(n=6)\end{array}$} & \multicolumn{2}{|c|}{ Adjusted $^{\mathrm{a}}$} \\
\hline & & & F value & $\mathrm{p}$ value \\
\hline \multicolumn{5}{|l|}{ ADAS at endpoint } \\
\hline Word recall & $7.05 \pm 1.65$ & $6.63 \pm 1.48$ & 0.001 & 0.972 \\
\hline Language & $0.38 \pm 1.06$ & $0.33 \pm 0.51$ & 1.150 & 0.309 \\
\hline Comprehension of spoken language & $0.38 \pm 1.06$ & $0.83 \pm 0.98$ & 1.226 & 0.300 \\
\hline Word finding difficulty & $0.38 \pm 10.06$ & $0.67 \pm 0.82$ & 1.832 & 0.209 \\
\hline Commands & $1.13 \pm .83$ & $1.00 \pm 1.10$ & 0.042 & 0.844 \\
\hline Object naming & $0.63 \pm 1.06$ & $0.33 \pm 0.52$ & 0.860 & 0.376 \\
\hline Constructional praxis & $0.88 \pm 0.35$ & $0.50 \pm 0.54$ & 0.353 & 0.574 \\
\hline Ideational praxis & $2.75 \pm 1.98$ & $3.50 \pm 1.22$ & 0 & 0.997 \\
\hline Orientation & $4.50 \pm 1.41$ & $2.67 \pm 1.86$ & 0.002 & 0.968 \\
\hline Word recognition & $4.74 \pm 2.26$ & $5.00 \pm 4.15$ & 2.942 & 0.137 \\
\hline Remembering test instructions & $1.13 \pm 2.10$ & $1.17 \pm 2.04$ & 0.139 & 0.720 \\
\hline ADAS total score & $23.91 \pm 9.02$ & $22.63 \pm 11.37$ & 0.780 & 0.411 \\
\hline \multicolumn{5}{|l|}{ SPECT at endpoint } \\
\hline \multicolumn{5}{|l|}{ Corpus callosum margin } \\
\hline Right & $0.753 \pm 0.144$ & $0.764 \pm 0.121$ & 7.296 & 0.022 \\
\hline Left & $0.737 \pm 0.152$ & $0.747 \pm 0.102$ & 4.702 & 0.560 \\
\hline \multicolumn{5}{|l|}{ Precentral gyrus } \\
\hline Right & $0.781 \pm 0.142$ & $0.805 \pm 0.104$ & 3.34 & 0.980 \\
\hline Left & $0.776 \pm 0.150$ & $0.834 \pm 0.083$ & 5.491 & 0.041 \\
\hline \multicolumn{5}{|l|}{ Center } \\
\hline Right & $0.777 \pm 0.150$ & $0.760 \pm 0.107$ & 1.682 & 0.224 \\
\hline Left & $0.769 \pm 0.156$ & $0.771 \pm 0.114$ & 1.309 & 0.279 \\
\hline \multicolumn{5}{|l|}{ Vertex } \\
\hline Right & $0.699 \pm 0.094$ & $0.664 \pm 0.094$ & 0.690 & 0.438 \\
\hline Left & $0.675 \pm 0.123$ & $0.666 \pm 0.083$ & 1.425 & 0.260 \\
\hline \multicolumn{5}{|l|}{ Angular gyrus } \\
\hline Right & $0.813 \pm 0.135$ & $0.785 \pm 0.125$ & 0.936 & 0.356 \\
\hline Left & $0.767 \pm 0.127$ & $0.793 \pm 0.122$ & 1.754 & 0.234 \\
\hline \multicolumn{5}{|l|}{ Temporal lobe } \\
\hline Right & $0.720 \pm 0.116$ & $0.749 \pm 0.074$ & 3.824 & 0.079 \\
\hline Left & $0.719 \pm 0.158$ & $0.765 \pm 0.582$ & 4.668 & 0.560 \\
\hline \multicolumn{5}{|l|}{ Posterior cerebrum } \\
\hline Right & $0.856 \pm 0.096$ & $0.863 \pm 0.094$ & 1.755 & 0.215 \\
\hline Left & $0.855 \pm 0.105$ & $0.891 \pm 0.090$ & 2.040 & 0.184 \\
\hline \multicolumn{5}{|l|}{ Around the corpus callosum } \\
\hline Right & $0.785 \pm 0.155$ & $0.783 \pm 0.135$ & 3.276 & 0.100 \\
\hline Left & $0.755 \pm 0.152$ & $0.777 \pm 0.020$ & 2.800 & 0.125 \\
\hline \multicolumn{5}{|l|}{ Lenticular nucleus } \\
\hline Right & $0.883 \pm 0.146$ & $0.949 \pm 0.196$ & 4.231 & 0.067 \\
\hline Left & $0.863 \pm 0.168$ & $0.952 \pm 0.194$ & 7.364 & 0.022 \\
\hline \multicolumn{5}{|l|}{ Thalamus } \\
\hline Right & $0.823 \pm 0.170$ & $0.787 \pm 0.122$ & 0.170 & 0.689 \\
\hline Left & $0.736 \pm 0.217$ & $0.808 \pm 0.151$ & 6.776 & 0.026 \\
\hline \multicolumn{5}{|l|}{ Hippocampus } \\
\hline Right & $0.572 \pm 0.112$ & $0.630 \pm 0.143$ & 11.045 & 0.008 \\
\hline Left & $0.563 \pm 0.159$ & $0.659 \pm 0.165$ & 2.454 & 0.148 \\
\hline
\end{tabular}

Values are mean $\pm \mathrm{SD}$. Boldface shows $\mathrm{p}<0.05$. ApoE4+ = Subjects with ApoE4; ApoE4- = subjects without ApoE4.

a 95\% confidence limits and p values are based on an ANCOVA model adjusted for sex and baseline score. 
Suwa et al.: Neuropsychological Evaluation and Cerebral Blood Flow Effects of ApoE4 in AD Patients after One Year of Treatment

Table 3. Results of the paired t test of ADAS scores between at baseline and at endpoint in subjects with and without ApoE4

\begin{tabular}{|c|c|c|c|c|c|c|c|c|c|}
\hline & \multicolumn{3}{|l|}{$\begin{array}{l}\text { ApoE4+ } \\
(n=8)\end{array}$} & \multicolumn{3}{|l|}{$\begin{array}{l}\text { ApoE4- } \\
(n=6)\end{array}$} & \multicolumn{3}{|c|}{$\begin{array}{l}\text { All subjects } \\
(\mathrm{n}=14)\end{array}$} \\
\hline & $\mathrm{p}$ value & t value & d.f. & $\mathrm{p}$ value & t value & d.f. & $\mathrm{p}$ value & t value & d.f. \\
\hline Word recall & 0.662 & 0.456 & 7 & 0.747 & -0.341 & 5 & 0.922 & -0.100 & 13 \\
\hline Language & 0.351 & -1.000 & 7 & 0.175 & -1.581 & 5 & 0.136 & -1.587 & 13 \\
\hline \multicolumn{10}{|l|}{ Comprehension of } \\
\hline spoken language & 0.563 & -0.607 & 7 & 0.695 & -0.415 & 5 & 0.459 & -0.763 & 13 \\
\hline Word finding difficulty & 0.351 & -1.000 & 7 & 0.203 & -1.464 & 5 & 0.111 & -1.710 & 13 \\
\hline Commands & 1.000 & 0 & 7 & 0.611 & -0.542 & 5 & 0.828 & -0.221 & 13 \\
\hline Object naming & 0.140 & -1.667 & 7 & 0.175 & -1.581 & 5 & 0.047 & -2.188 & 13 \\
\hline Constructional praxis & 0.351 & -1.000 & 7 & 0.076 & 2.236 & 5 & 0.720 & 0.366 & 13 \\
\hline Ideational praxis & 0.140 & -1.667 & 7 & 0.028 & -3.051 & 5 & 0.009 & -3.068 & 13 \\
\hline Orientation & 0.121 & -1.764 & 7 & 0.253 & -1.291 & 5 & 0.043 & -2.248 & 13 \\
\hline Word recognition & 0.345 & -1.014 & 7 & 0.747 & -0.341 & 5 & 0.444 & -0.790 & 13 \\
\hline Remembering test instructions & 0.317 & -1.078 & 7 & 0.363 & -1.000 & 5 & 0.152 & -1.522 & 13 \\
\hline ADAS total score & 0.058 & -2.269 & 7 & 0.222 & -1.396 & 5 & 0.021 & -2.624 & 13 \\
\hline
\end{tabular}

Boldface shows $\mathrm{p}<0.05$. ApoE4+ = Subjects with ApoE4; ApoE4- = subjects without ApoE4.

those with ApoE4 showed no significant difference. On the other hand, subjects without ApoE4 showed significant deterioration in ideational praxis $(p=0.028)$ (table 3$)$.

\section{SPECT}

All patients showed significantly reduced blood flow in the left and right angular gyri $(\mathrm{p}=$ 0.01 and 0.015$)$, the left and right lenticular nuclei ( $p=0.029$ and 0.043$)$, and right thalamus $(p=0.005)$. In particular, subjects with ApoE4 showed significantly reduced blood flow in the left and right angular gyri ( $p=0.006$ and 0.003$)$, left and right lenticular nuclei $(p=0.017$ and $0.032)$, right thalamus $(p=0.02)$, and right hippocampus $(p=0.044)$. In contrast, subjects without ApoE4 showed no significant differences in blood flow between regions (table 4).

\section{Discussion}

In this study, we examined the effects of carrying or not carrying ApoE4 on ADAS cognitive function scores and the cerebral blood flow rate as measured by SPECT.

Difference at Endpoint between the Groups with and without ApoE4 Revealed by ANCOVA

Subjects with ApoE4 showed significantly reduced blood flow at endpoint in the right hippocampus, right corpus callosum margin, left precentral gyrus, left lenticular nucleus, and left thalamus compared with subjects without ApoE4 at endpoint. On the other hand, the ADAS scores including subscales at endpoint in the subjects with or without ApoE4 did not indicate any difference.

Significant cerebral metabolic rate for glucose has been reported to decline in thalamus [21], and significantly decreased functional connectivity was found in thalamus and basal ganglia including lenticular nuclei [22] and showed markedly reduced metabolism in the parietal lobe and temporal lobe including hippocampus as compared to patients without ApoE4 [23, 24]. 
Suwa et al.: Neuropsychological Evaluation and Cerebral Blood Flow Effects of ApoE4 in AD Patients after One Year of Treatment

Table 4. Results of the paired t test of cerebral blood flow measured by SPECT between at baseline and at endpoint in subjects with and without ApoE4

\begin{tabular}{|c|c|c|c|c|c|c|c|c|c|}
\hline & \multicolumn{3}{|l|}{$\begin{array}{l}\text { ApoE4+ } \\
(n=8)\end{array}$} & \multicolumn{3}{|l|}{$\begin{array}{l}\text { ApoE4- } \\
(n=6)\end{array}$} & \multicolumn{3}{|c|}{$\begin{array}{l}\text { All subjects } \\
(\mathrm{n}=14)\end{array}$} \\
\hline & $\mathrm{p}$ value & $\mathrm{t}$ value & d.f. & $\mathrm{p}$ value & t value & d.f. & $\mathrm{p}$ value & t value & d.f. \\
\hline \multicolumn{10}{|c|}{ Corpus callosum margin } \\
\hline Right & 0.110 & 1.829 & 7 & 0.302 & -1.150 & 5 & 0.376 & 0.917 & 13 \\
\hline Left & 0.115 & 1.797 & 7 & 0.485 & -0.754 & 5 & 0.248 & 1.210 & 13 \\
\hline \multicolumn{10}{|c|}{ Precentral gyrus } \\
\hline Right & 0.065 & 2.192 & 7 & 0.869 & -0.174 & 5 & 0.130 & 1.616 & 13 \\
\hline Left & 0.120 & 1.773 & 7 & 0.355 & -1.018 & 5 & 0.405 & 0.861 & 13 \\
\hline \multicolumn{10}{|l|}{ Center } \\
\hline Right & 0.128 & 1.726 & 7 & 0.909 & -0.120 & 5 & 0.207 & 1.329 & 13 \\
\hline Left & 0.536 & 0.650 & 7 & 0.552 & -0.638 & 5 & 0.770 & 0.299 & 13 \\
\hline \multicolumn{10}{|l|}{ Vertex } \\
\hline Right & 0.153 & 1.602 & 7 & 0.905 & 0.126 & 5 & 0.229 & 1.263 & 13 \\
\hline Left & 0.215 & 1.363 & 7 & 0.657 & -0.471 & 5 & 0.482 & 0.724 & 13 \\
\hline \multicolumn{10}{|c|}{ Angular gyrus } \\
\hline Right & 0.006 & 3.845 & 7 & 0.359 & 1.010 & 5 & 0.010 & 3.015 & 13 \\
\hline Left & 0.003 & 4.495 & 7 & 0.531 & 0.672 & 5 & 0.015 & 2.806 & 13 \\
\hline \multicolumn{10}{|c|}{ Temporal lobe } \\
\hline Right & 0.023 & 2.886 & 7 & 0.898 & 0.135 & 5 & 0.057 & 2.089 & 13 \\
\hline Left & 0.060 & 2.238 & 7 & 0.920 & -0.106 & 5 & 0.113 & 1.702 & 13 \\
\hline \multicolumn{10}{|c|}{ Posterior cerebrum } \\
\hline Right & 0.087 & 1.988 & 7 & 0.370 & 0.984 & 5 & 0.052 & 2.139 & 13 \\
\hline Left & 0.162 & 1.563 & 7 & 0.919 & 0.107 & 5 & 0.251 & 1.200 & 13 \\
\hline \multicolumn{10}{|c|}{ Around the corpus callosum } \\
\hline Right & 0.119 & 1.775 & 7 & 0.910 & -0.119 & 5 & 0.187 & 1.395 & 13 \\
\hline Left & 0.064 & 2.200 & 7 & 0.742 & 0.348 & 5 & 0.074 & 1.939 & 13 \\
\hline \multicolumn{10}{|c|}{ Lenticular nucleus } \\
\hline Right & 0.017 & 3.109 & 7 & 0.747 & 0.341 & 5 & 0.029 & 2.457 & 13 \\
\hline Left & 0.032 & 2.660 & 7 & 0.716 & 0.385 & 5 & 0.043 & 2.248 & 13 \\
\hline \multicolumn{10}{|l|}{ Thalamus } \\
\hline Right & 0.020 & 3.013 & 7 & 0.170 & 1.601 & 5 & 0.005 & 3.373 & 13 \\
\hline Left & 0.078 & 2.062 & 7 & 0.774 & -0.303 & 5 & 0.160 & 1.490 & 13 \\
\hline \multicolumn{10}{|c|}{ Hippocampus } \\
\hline Right & 0.044 & 2.457 & 7 & 0.788 & 0.283 & 5 & 0.055 & 2.111 & 13 \\
\hline Left & 0.425 & 0.848 & 7 & 0.545 & -0.649 & 5 & 0.638 & 0.482 & 13 \\
\hline
\end{tabular}

Boldface shows $\mathrm{p}<0.05$. ApoE4+ = Subjects with ApoE4; ApoE4- = subjects without ApoE4.

Regarding the hippocampus in particular, Hashimoto et al. [25] proved that hippocampal volume in $\mathrm{AD}$ patients was related to ApoE4. The reduction of cerebral blood flow may result from the reduction of the hippocampus volume, which could be attributed to the different physiological changes between ApoE carriers and noncarriers.

The precentral gyrus is the posterior aspect of the frontal lobe. The number of papers showing that $\mathrm{AD}$ patients have some reduction in frontal lobes is lower than that of those showing some reduction in temporal and parietal lobes. One study using positron emission tomography found that ApoE4 carriers had lower activation in parahippocampal and right precentral gyrus during a recognition memory task. Despite the fact that the lateralization of our findings did not correspond exactly with those reported by Scarmeas et al. [26], both these results highlight that the precentral gyrus may be an important area for the effects of 

Suwa et al.: Neuropsychological Evaluation and Cerebral Blood Flow Effects of ApoE4
in AD Patients after One Year of Treatment

ApoE4. These ANCOVA results indicate the possibility that the effects of ApoE4 was observed in blood flow rates measured by SPECT compared with ADAS at endpoint.

Time Course Changes in the Group with ApoE4 Revealed by Paired t Tests

Changes at endpoint compared to baseline, in patients with ApoE4, showed no significant changes in ADAS total scores or subscale scores during 1 year. However, they showed significantly reduced blood flow in bilateral angular gyri, right temporal lobes, bilateral lenticular nuclei, right thalamus, and right hippocampus on SPECT. These results partly correspond to a previous report showing that subjects who carried ApoE4 had stronger amyloid beta plaque deposition in temporoparietal cortex, including a part of the angular gyrus [21,27].

\section{Time Course Changes in the Group without ApoE4 Revealed by Paired t Tests}

In analogy to the previous analysis described above, blood flow at endpoint compared to baseline with paired t tests in the patients without ApoE4 showed significant deterioration of the ideational praxis in ADAS subscale, whereas no significant change was observed in SPECT images. These results for cognitive function did not correspond to a previous report showing that assignments of object naming, cognition speed, and executive function became more impaired in patients without ApoE4 as compared to those with ApoE4 [28]. This difference between our and a previous paper may be due to the fact that the subjects in the study by Wolk and Dickerson [28] focused on mild AD, and the cognitive function tests were different from the ones in the present study.

\section{Joint Interpretation of the Results of ANCOVA and $t$ Tests}

The results obtained using ANCOVA and t tests indicate that effects of ApoE4 were observed with SPECT compared with ADAS. The subjects with ApoE4 showed significant blood flow changes, especially in temporal and hippocampal areas, indicating that these areas are possibly especially sensitive for testing AD patients with ApoE4. Since differences in decreases in cognitive function and in cerebral blood flow scintigraphy could be observed by classifying patients by ApoE phenotype, the treatment with DNP may affect the cognitive function despite the progression of organic changes in patients with ApoE4. We can also propose that ApoE phenotype testing enables more accurate evaluation of the status and prognosis of the brain state in patients with $\mathrm{AD}$. Taking these results together, it is evident from these findings that ApoE4 is an important factor for evaluating the progress of AD, especially when using SPECT.

\section{Limitations}

Despite our findings, this study has some limitations and future challenges remain. First, cognitive function in AD patients is considered to be affected by the presence or absence of physical disorders, their pre-AD lifestyle history, and the environment of treatment and care. As we were unable to control these factors, it cannot be ruled out that this may have biased our results by reducing statistical power. Second, due to the small sample size, especially for those without ApoE4, a future project may be indicated to replicate this work with a larger sample size.

\section{Acknowledgments}

This project was sponsored by a grant from the Medical Research Foundation for Senile Dementia of Osaka. We thank Misa Suzuki and Robert D. Pascual-Marqui for help in data collection and statistical analysis. 


\section{Disclosure Statement}

M. Yoshimura has received speaker's honoraria from Eisai. T. Kinoshita has received grant/research support or honoraria from Eisai.

\section{References}

1 McKhann G, Drachman D, Folstein M, Katzman R, Price D, Stadlan EM: Clinical diagnosis of Alzheimer's disease report of the NINCDS-ADRDA work group under the auspices of Department of Health and Human Services Task Force on Alzheimer's Disease. Neurology 1984;34:939-944.

2 Ritchie CW, Ames D, Clayton T, Lai R: Metaanalysis of randomized trials of the efficacy and safety of donepezil, galantamine, and rivastigmine for the treatment of Alzheimer disease. Am J Geriatr Psychiatry 2004;12:358369.

3 Folstein MF, Folstein SE, McHugh PR: 'Mini-Mental State'. A practical method for grading the cognitive state of patients for the clinician. J Psychiatr Res 1975;12:189-198.

4 Rosen WG, Mohs RC, Davis KL: A new rating scale for Alzheimer's disease. Am J Psychiatry 1984;141:13561364.

5 Small BJ, Viitanen M, Backman L: Mini-Mental State Examination item scores as predictors of Alzheimer's disease: incidence data from the Kungsholmen Project, Stockholm. J Gerontol A Biol Sci Med Sci 1997; 52:M299-M304.

6 Yamagishi T, Sato T, Sato A, Imamura T: Cognitive factors affecting free recall, cued recall, and recognition tasks in Alzheimer's disease. Dement Geriatr Cogn Disord Extra 2012;2:278-285.

$>7$ Matsuda H, Mizumura S, Nagao T, Ota T, Iizuka T, Nemoto K, Takemura N, Arai H, Homma A: Automated discrimination between very early Alzheimer disease and controls using an easy z-score imaging system for multicenter brain perfusion single-photon emission tomography. AJNR Am J Neuroradiol 2007;28:731-736.

$>8$ Minoshima S, Frey KA, Koeppe RA, Foster NL, Kuhl DE: A diagnostic approach in Alzheimer's disease using three-dimensional stereotactic surface projections of fluorine-18-FDG PET. J Nucl Med1995;36:1238-1248.

-9 Farrer LA, Cupples LA, Haines JL, Hyman B, Kukull WA, Mayeux R, Myers RH, Pericak-Vance MA, Risch N, van Duijn CM: Effects of age, sex, and ethnicity on the association between apolipoprotein E genotype and Alzheimer disease: a meta-analysis. JAMA 1997;278:1349-1356.

-10 Corder EH, Saunders AM, Strittmatter WJ, Schmechel DE, Gaskell PC, Small GW, Roses AD, Haines JL, PericakVance MA: Gene dose of apolipoprotein E type 4 allele and the risk of Alzheimer's disease in late onset families. Science 1993;261:921-923.

11 Saunders AM, Strittmatter WJ, Schmechel D, George-Hyslop PH, Pericak-Vance MA, Joo SH, Rosi BL, Gusella JF, Crapper-MacLachlan DR, Alberts MJ, et al: Association of apolipoprotein E allele epsilon 4 with late-onset familial and sporadic Alzheimer's disease. Neurology 1993;43:1467-1472.

-12 van der Flier WM, Staekenborg S, Pijnenburg YA, Gillissen F, Romkes R, Kok A, Bouwman FH, Scheltens P: Apolipoprotein E genotype influences presence and severity of delusions and aggressive behavior in Alzheimer disease. Dement Geriatr Cogn Disord 2007;23:42-46.

13 Sakamoto S, Matsuda H, Asada T, Ohnishi T, Nakano S, Kanetaka H, Takasaki M: Apolipoprotein E genotype and early Alzheimer's disease: a longitudinal SPECT study. J Neuroimaging 2003;13:113-123.

14 McKhann GM, Knopman DS, Chertkow H, Hyman BT, Jack CR Jr, Kawas CH, Klunk WE, Koroshetz WJ, Manly JJ, Mayeux R, Mohs RC, Morris JC, Rossor MN, Scheltens P, Carrillo MC, Thies B, Weintraub S, Phelps CH: The diagnosis of dementia due to Alzheimer's disease: recommendations from the National Institute on AgingAlzheimer's Association workgroups on diagnostic guidelines for Alzheimer's disease. Alzheimers Dement 2011;7:263-269.

15 Kanaya K, Abe S, Sakai M, Fujii H, Iwamoto T: Changes in cognitive functions of patients with dementia of the Alzheimer type following long-term administration of donepezil hydrochloride: relating to changes attributable to differences in apolipoprotein E phenotype. Geriatr Gerontol Int 2010;10:25-31.

16 Samuraki M, Matsunari I, Chen W-P, Shima K, Yanase D, Takeda N, Matsuda H, Yamada M: Glucose metabolism and gray-matter concentration in apolipoprotein E $\varepsilon 4$ positive normal subjects. Neurobiol Aging 2012;33: 2321-2323.

17 Homma A: Assessment and treatment of patients with dementia of the Alzheimer type (in Japanese). Nihon Ronen Igakkai Zasshi 1992;29:264-270.

-18 Takeuchi R, Sengoku T, Matsumura K: Usefulness of fully automated constant ROI analysis software for the brain: 3DSRT and FineSRT. Radiat Med 2006;24:538-544.

19 Takeuchi R, Matsuda H, Yoshioka K, Yonekura Y: Cerebral blood flow SPET in transient global amnesia with automated ROI analysis by 3DSRT. Eur J Nucl Med Mol Imaging 2004;31:578-589.

20 Singh NK, Banerjee BD, Bala K, Mitrabasu, Dung Dung AA, Chhillar N: APOE and LRPAP1 gene polymorphism and risk of Parkinson's disease. Neurol Sci 2014;35:1075-1081.

21 Reiman EM, Caselli RJ, Chen K, Alexander GE, Bandy D, Frost J: Declining brain activity in cognitively normal apolipoprotein E $\varepsilon 4$ heterozygotes: a foundation for using positron emission tomography to efficiently test treatments to prevent Alzheimer's disease. Proc Natl Acad Sci USA 2001;98:3334-3339. 
22 Li W, Antuono PG, Xie C, Chen G, Jones JL, Ward BD, Singh SP, Franczak MB, Goveas JS, Li SJ: Aberrant functional connectivity in Papez circuit correlates with memory performance in cognitively intact middle-aged APOE4 carriers. Cortex 2014;57:167-176.

-23 Drzezga A, Riemenschneider M, Strassner B, Grimmer T, Peller M, Knoll A, Wagenpfeil S, Minoshima S, Schwaiger M, Kurz A: Cerebral glucose metabolism in patients with AD and different APOE genotypes. Neurology 2005;64:102-107.

24 Tanaka S, Kawamata J, Shimohama S, Akaki H, Akiguchi I, Kimura J, Ueda K: Inferior temporal lobe atrophy and APOE genotypes in Alzheimer's disease. X-ray computed tomography, magnetic resonance imaging and Xe-133 SPECT studies. Dement Geriatr Cogn Disord 1998;9:90-98.

25 Hashimoto M, Yasuda M, Tanimukai S, Matsui M, Hirono N, Kazui H, Mori E: Apolipoprotein E epsilon 4 and the pattern of regional brain atrophy in Alzheimer's disease. Neurology 2001;57:1461-1466.

26 Scarmeas N, Anderson KE, Hilton J, Park A, Habeck C, Flynn J, Tycko B, Stern Y: APOE-dependent PET patterns of brain activation in Alzheimer disease. Neurology 2004;63:913-915.

-27 Drzezga A, Grimmer T, Henriksen G, Muhlau M, Perneczky R, Miederer I, Praus C, Sorg C, Wohlschlager A, Riemenschneider M, Wester HJ, Foerstl H, Schwaiger M, Kurz A: Effect of APOE genotype on amyloid plaque load and gray matter volume in Alzheimer disease. Neurology 2009;72:1487-1494.

28 Wolk DA, Dickerson BC: Apolipoprotein E (APOE) genotype has dissociable effects on memory and attentional-executive network function in Alzheimer's disease. Proc Natl Acad Sci USA 2010;107:10256-10261. 